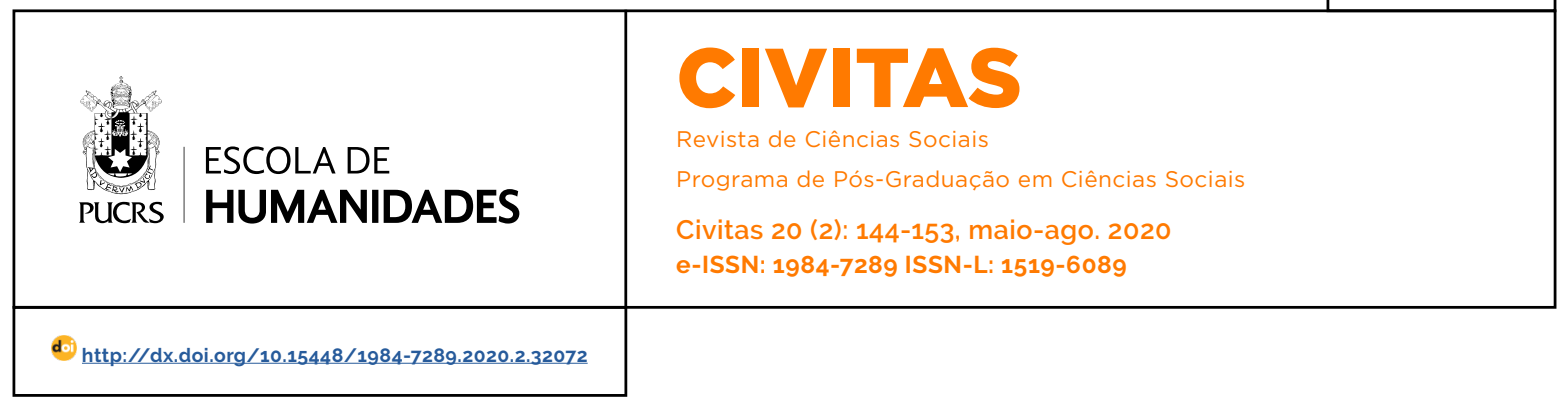

DOSSIÊ: MEIO AMBIENTE EM DISPUTA

\title{
Na encruzilhada entre "emancipação" e dominação: a narrativa ambientalista global e as politicas desenvolvimentistas de África
}

\author{
Between "emancipation" and domination: the global environmental narrative and the \\ development policies of Africa \\ Entre la "emancipación" e dominación: la narrativa ambientalista global y las políticas \\ desarrollistas en África
}

\section{André Victorino Mindoso ${ }^{1}$ orcid.org/0000-0003-2969-5187 amindoso@hotmail.com}

Recebido em: 27 set. 2018. Aprovado em: 11 mar. 2020. Publicado em: 4 ago. 2020

\section{(c) (1)}

Artigo está licenciado sob forma de uma licença Creative Commons Atribuição 4.0 Internacional.
Resumo: O artigo se propõe a compreender a construção da narrativa ambientalista global e o lugar que o continente africano nela ocupa. Para o efeito, analisa documentos produzidos pelas Nações Unidas (ONU) e União Africana, entre 1972 e 2002, e que versam sobre a questão do desenvolvimento, natureza e meio ambiente. Os resultados da análise indicam que a dita narrativa obrigava os países a incorporarem a dimensão ambiental em suas políticas desenvolvimentistas. Dada a situação de pobreza dominante em África, contudo, o continente era encarado como incapaz de preservar a natureza, ao que deveria estar sob a tutela de países do norte-global. Sugeria-se que estes, por via da expansão de seu capital econômico e assistencialismo técnico, seriam capazes de eliminar a pobreza dos africanos e, consequentemente, os impediriam de agredir a natureza. Essa situação, contudo, conflitava com a agenda desenvolvimentista africana iniciada no pós-independência, e que via na exploração da natureza o caminho pelo qual alcançaria a sua emancipação econômica.

Palavras-chave: Desenvolvimento. Narrativa ambientalista global. África.

Abstract: The article aims to understand the construction of the global environmentalist narrative and the place that the African continent occupies in it. To this end, it analyzes documents produced by the United Nations and the African Union, between 1972 and 2002, and which deal with the issue of development, nature and the environment. The results of the analysis indicate that such a narrative obliged countries to incorporate the environmental dimension in their developmental policies. Given the prevailing poverty situation in Africa, however, the continent was seen as incapable of preserving nature and because of that should be under the tutelage of countries of the global north. It was suggested that these countries, through the expansion of their economic capital and technical assistance, would be able to eliminate the poverty of Africans and, consequently, prevent them from attacking nature. This situation, however, conflicted with the African development agenda initiated in the post-independence period, which saw in the exploration of nature the path by which the continent would achieve its economic emancipation. Keywords: Development. Global environmental narrative. Africa.

Resumen: El trabajo se propone comprender la construcción de la narrativa ambientalista global y el lugar que el continente africano ocupa en ella. Con este fin, analiza documentos producidos por las Naciones Unidas y la Unión Africana (1972-2002) y que abordan la cuestión del desarrollo, naturaleza y el medio ambiente. Los resultados del análisis indican que dicha narrativa obligó a los países a incorporar la dimensión ambiental en sus politicas de desarrollo. Sin embargo, dada la situación de pobreza prevaleciente en África, el continente era visto como incapaz de preservar la naturaleza y que por eso deberia estar bajo la tutela de 
los paises del norte global. En este sentido se sugirió que, a través de la expansión de su capital económico y asistencia técnica, los países del norte-global podrian eliminar la pobreza de los africanos y, en consecuencia, evitar que atacaran la naturaleza. Esta situación entró en conflicto con la agenda desarrollista africana que veía en la exploración de la naturaleza el camino por el cual lograría su emancipación económica.

Palabras clave: Desarrollo. Narrativa ambientalista global. África.

\section{Introdução}

A relação mais significativa que a África estabeleceu com o mundo no século 19, foi sobretudo, com a Europa. Tratava-se de uma relação de subjugação colonial daquele continente, mas que a elite dirigente europeia a encarava como uma necessidade civilizatória, norteada por uma suposta irmandade cristã para com as populações nativas africanas (Moreira 1956 e 1961; Monteiro 1939). Contrariando essa narrativa, nos meados do século surge outra, escrita pelos próprios africanos sediados em África ou na diáspora europeia e norte-americana. Estava em causa um exercício que tinha como objetivo mais amplo, o de denunciar a narrativa civilizatória europeia, mostrando que ela, longe de encerrar um interesse de irmandade dos europeus para com os povos africanos, traduzia-se em um projeto colonialista que tinha como intuito a sua exploração e dominação (entre outros, Mondlane 1995: Cabral 1980; Nyerere 1968).

Com as independências politicas do continente, havidas sobretudo nas décadas de 1950 e 1960, e que resultaram parcialmente do sucesso da narrativa anticolonial acima indicada, assiste-se a uma nova fase na relação entre a África e as suas antigas metrópoles coloniais. Com efeito, o fim da dicotomia colono/colonizado, civilizado/não civilizado, colono/indigena, bem como outras categorias classificatórias que sugerissem a diferenciação e hierarquização da relação entre a Europa e África, possibilitou a emergência de novas narrativas globais que passaram a permear a relação entre antigos colonizadores e antigos colonizados.

É nesse contexto que a Organização das Nações Unidas (ONU), capitaneada principalmente pelos Estados Unidos da América, passou a ser um poder cada vez mais presente no mundo (Dos
Santos 2011). Como nota Maurice Bertrand (2004), a ONU, nos primórdios de sua formação, tinha como um de seus objetivos principais, o de construir um mundo mais integrado e harmonioso, passando a se constituir em importante agente fazedor de politicas globais. Uma das que passou a ocupar a atenção desta organização - e que ela pretendia expandir sobretudo para os paises do sul-global era a da incorporação da ideia de sustentabilidade ambiental nas práticas desenvolvimentistas.

Acontece que, como sugere Bertrand (2004), a forma de tomada de decisão em organizações multilaterais, como a ONU, não era nem tem sido nada consensual, sendo que as resoluções dai emanadas refletiam mais o jogo de forças económicas e políticas entre seus membros, onde os paises do norte-global, especialmente os EUA e secundariamente a Europa ocidental, eram os que tomavam maior protagonismo. Os paises do sul-global, dado o lugar marginal que historicamente lhes fora relegado, especialmente pela colonização, não tinham poder suficiente para influenciar as políticas globais. É nesse sentido que, analisando o lugar da África na ONU na década de 1960, Thomas Hovet Jr. (1964) mostra que os paises do continente não tinham espaço de manobra suficiente dentro da organização que os permitisse fazer vincar seus posicionamentos sobre os consensos ai alcançados, sobretudo no que dizia respeito às questões de segurança e políticas globais de desenvolvimento.

O dado que acabamos de mencionar é deveras significativo para esta discussão pois, no periodo da consolidação da ONU, principalmente entre 1950 e 1980, a África estava formalmente saindo de uma longeva situação colonial, onde, sob a coordenação da então constituída Organização da Unidade Africana (OUA), estava se desdobrando em esboçar agendas de desenvolvimento para os países que a integravam. Como enfatiza Deepak Nayyar (2013), havia chegado para a elite dirigente do continente, o periodo da efetivação do desenvolvimento que a colonização europeia não havia possibilitado à maior parte de seus cidadãos. Essa pretensão, como se verá ao longo do artigo, encontra-se explicitamente colocada em diferentes diretivas traçadas pelos líderes do 
continente e que viam na natureza um importante ativo para o seu desenvolvimento.

Como que um balde de água fria, os novos ares dos anos de 1970, caracterizados pela emergência de movimentos sociais ambientalistas em países do norte-global (Hannigan 2006; Giddens 2008), colocaram a narrativa ambientalista na agenda de suas elites dirigentes e econômicas. É nesse contexto que em 1972, na cidade de Estocolmo, a ONU definia a nova política global sobre desenvolvimento, natureza e meio ambiente, o que acabou por se constituir, pelo menos discursivamente, em uma nova forma de relacionamento entre os países do norte-global e os do sul-global.

Enrique Leff (2006), contudo, denuncia a natureza colonizante dessa nova forma de relacionamento. No seu entender, os paises do norte-global, dado o poderio que detinham no processo de tomada de decisão em organizações como a ONU, usavam essas instâncias para impor um discurso que visava legitimar a expansão do neoliberalismo para os países do sul sob o simulacro da necessidade de uma nova agenda desenvolvimentista global. Em suma, os países do norte-global passaram a domesticar as reivindicações dos movimentos ambientalistas e criaram uma narrativa em que se colocavam no lugar de tutores do desenvolvimento ambientalmente sustentável dos países africanos, quando na verdade, tratava-se de uma estratégia para adentrar o neoliberalismo nos paises do continente.

Neste artigo temos como objetivo compreender o processo de construção da narrativa ambientalista global e o lugar que o continente africano nela ocupa. Metodologicamente nos baseamos na análise documental de algumas das principais resoluções sobre desenvolvimento, natureza e meio ambiente, emanadas de conferências das Nações Unidas e União Africana entre 1972 e 2002.

Em termos expositivos, dividimos o artigo em dois momentos. Começamos por analisar as resoluções das Nações Unidas, designadamente as de Estocolmo (1972), Rio de Janeiro (1992) e
Johanesburgo (2002), com o intuito de percebermos a forma como se deu a construção da narrativa ambientalista global e o lugar nela reservado ao continente africano. Em um segundo momento, e tomando para análise as resoluções da União Africana, incluindo a sua iniciativa Nova Pareceria para o Desenvolvimento de África (NEPAD), analisamos a forma como as lideranças do continente, ávidas em esboçarem politicas desenvolvimentistas autóctones e emancipatórias, posicionam-se face à narrativa ambiental global.

\section{Estocolmo e a inauguração da narrativa ambientalista global}

A primeira grande conferência sobre o meio ambiente e desenvolvimento teve lugar em um pais do norte-global, concretamente na Suécia. Nessa conferência, que decorreu na cidade de Estocolmo, de 5 a 16 de junho de 1972, surgiu uma resolução que introduzia a diretiva global de se tomar sempre em atenção as questões ambientais nas políticas e práticas desenvolvimentistas dos paises, como forma de se salvaguardar a sobrevivência da espécie humana. ${ }^{2}$

Essa conferência, contudo, foi resultado de um contexto histórico caracterizado pela emergência, sobretudo na Europa e na América do Norte, de diferentes movimentos de pressão social e política que sugeriam uma nova forma de se encarar os processos de desenvolvimento e industrialização então dominantes que não tomavam em consideração a proteção da natureza e de seus ecossistemas (Giddens 2008; Hannigan 2006; Acslard 2002). Essa pressão, de alguma forma, teve consequências no sistema de relações internacionais, na medida em que, a questão ambiental mereceu especial atenção em uma conferência de chefes de estado e de governo:

A proteção e melhoria do meio ambiente humano
é a questão crucial que tem afetado as pessoas
e o desenvolvimento econômico pelo mundo. É
desejo das pessoas de todo o mundo e obrigação
dos governos que tal proteção e melhoria do
meio ambiente ocorra (United Nations 1972,3$)^{3}{ }^{3}$

\footnotetext{
United Nations. 1972. Report of the United Nations Conference on the Human Environment. Stockholm, 5-16 Jun. Acessado em 10 jul 2018, https://digitallibrary.un.org/record/523249.

3 United Nations. 1972. Report of the United Nations Conference on the Human Environment. Stockholm, 5-16 Jun. Acessado em 10 jul. 2018, https://digitallibrary.un.org/record/523249.
} 
Analisando o documento mais a fundo, constatamos que o conteúdo do mesmo ressalta a necessidade de se superar os principais problemas ambientais de então, bem como se identificam as causas de sua ocorrência:

Nas mais diferentes regiões do planeta, vemos evidências crescentes de males provocados pelo homem: niveis assustadores de poluição da água, ar, terra e dos seres vivos; um crescente e indesejado desequilibrio ecológico e da biosfera; destruição de recursos não renováveis e; deficiências graves e prejudiciais à saúde física, mental e social do homem no meio ambiente, particularmente no que diz respeito ao local de moradia e trabalho [...]. Muitos dos problemas ambientais nos paises em desenvolvimento têm sido causados pelo subdesenvolvimento que thes caracteriza, sendo que milhões de pessoas continuam não tendo o mínimo necessário para uma vida humana decente. Elas são carentes de alimentação, vestuário, habitação, educação, saúde e saneamento. Daí que os paises em vias de desenvolvimento devem direcionar seus esforços ao desenvolvimento, tendo em conta as suas prioridades, mas sem colocar em causa a salvaguarda e melhoria do meio ambiente. Do mesmo modo, os paises industrializados devem se esforçar em reduzir a assimetria entre eles e os países em vias de desenvolvimento. Nos paises industrializados, os problemas ambientais estão genericamente relacionados com o desenvolvimento industrial e tecnológico (United Nations 1972, 3). ${ }^{4}$

A partir da citação acima, fica claro que a narrativa ambientalista global, inaugurada em Estocolmo, considerava existirem diferenças na natureza dos problemas ambientais. Nos países considerados desenvolvidos (no norte-global), sua causa era o desenvolvimento da indústria aí predominante, enquanto que, no sul-global eles eram causados pelo seu subdesenvolvimento, caracterizado pela carestia generalizada de alimentação, vestuário, educação, saúde e salubridade. Ou seja, enquanto, no primeiro caso, o excesso da produção industrial estava na base da origem e agudização de problemas ambientais, no segundo, a sua escassez é que explicava a agressão do homem à natureza.
Se as causas dos problemas ambientais estavam identificadas, a sua solução também aparece apresentada no documento em análise. Nele fica claro que cabia aos paises do norte-global prestar apoio aos do sul, fazendo com que esses reduzissem seus indices de pobreza:

Os problemas ambientais provocados pela situação de subdesenvolvimento e desastres naturais podem ser solucionados pelo estímulo ao desenvolvimento através da transferência de quantidades substanciais de recursos financeiros e assistência tecnológica como complemento aos esforços domésticos empreendidos pelos países em vias de desenvolvimento [...] (United Nations 1972, 4). ${ }^{5}$

Nota-se, desta forma, que a narrativa ambientalista global em causa dá maior protagonismo aos países do norte-global na busca por um desenvolvimento ambientalmente sustentável. Eles deveriam mobilizar recursos financeiros e assistência técnica, direcionando-os aos países do sul-global na expectativa de que esses não agrediriam a natureza e o meio ambiente alegando estar combatendo a pobreza ai reinante. Surge aqui, em nosso entender, uma relação de tutela, onde, os países do norte-global passavam a ter responsabilidades sobre os do sul, no que diz respeito às questões do desenvolvimento e meio ambiente.

Essa ideia de se verem os países do norte- global como agentes tutelares das questões ambientais dos países ditos subdesenvolvidos é importante para que possamos compreender o lugar atribuído à África na narrativa ambientalista global então em construção. Esse continente, nos anos de 1970 estava ainda se tornando politicamente independente do colonialismo europeu. Tal colonialismo, como já mencionamos neste artigo, sustentava-se em uma narrativa civilizatória que sugeria que os africanos deveriam estar sujeitos a uma tutela política e administrativa de diferentes agentes coloniais europeus. No periodo da criação da narrativa ambientalista global do pós-independência, contudo, a África,

\footnotetext{
4 United Nations. 1972. Report of the United Nations Conference on the Human Environment. Stockholm, 5-16 Jun. Acessado em 10 jul. 2018, https://digitallibrary.un.org/record/523249.

5 United Nations. 1972. Report of the United Nations Conference on the Human Environment. Stockholm, 5-16 Jun. Acessado em 10 jul. 2018, https://digitallibrary.un.org/record/523249.
} 
assim como outros países do sul-global, passou a ser representada como estando sujeita à tutela ambiental e desenvolvimentista dos países do norte-global, e especialmente pelo imperialismo norte americano. Esse país, de acordo com Arturo Escobar (2004), estava seguindo uma política internacional que visava, a todo o custo, alargar a sua área de influência pelo mundo, expandindo a ideologia neoliberal, o comércio livre, a democracia e, acrescentamos, o discurso ambientalista, enquanto a única saida para o seu desenvolvimento. Aqui, contudo, a presença do bloco socialista no continente, que tinha aí uma grande influência em vários países, não facilitou a entrada desse imperialismo estadunidense, o que veio a acontecer de forma mais efetiva no pós-1990, dado o colapso desse bloco.

\section{Os consensos do Rio: globalização, neoliberalismo e a ressignificação da narrativa ambientalista global}

Vinte anos após a realização da conferência de Estocolmo, outra teve lugar no Rio de Janeiro, de 3 a 14 de junho de 1992. De um modo geral, nessa conferência a ideia de que o desenvolvimento dos países deveria ser feito tendo em conta a preservação da natureza como condição da sobrevivência da humanidade continuou estando presente na narrativa ambientalista global. O conteúdo de tal narrativa, contudo, sofreu algumas alterações. A primeira delas é a de que os problemas ambientais - que em Estocolmo eram tidos como resultantes da extrema industrialização, no caso de paises desenvolvidos, e da pobreza extrema, no caso dos países subdesenvolvidos - no Rio passaram a ser vistos de uma forma globalizada:

A humanidade chegou a um estágio determinante da sua história onde se assiste à perpetuação de disparidades no interior das nações assim como entre elas. A agudização da pobreza, fome e analfabetismo é uma realidade. Assiste-se igualmente à deterioração dos ecossistemas dos quais dependemos para o nosso bem estar. Apesar disso, uma abordagem integrada entre meio ambiente e questões do desenvolvimento levará à satisfação das necessidades básicas, melhoria da qualidade de vida para todos, conservação e melhor gestão dos ecossistemas e, um futuro seguro e próspero. Nenhum pais pode alcançar esse ideal de forma isolada, mas, juntos podemos, por via de uma pareceria global pelo desenvolvimento sustentável (United Nations 1992, 12). ${ }^{6}$

Essa globalização dos problemas ambientais pode ser percebida por um dado significativo. As questões da mudança climática e a preservação da biodiversidade passaram a fazer parte do leque de problemas ambientais do final da década de 1980 e início de 1990, aparecendo recorrentemente mencionado na resolução do Rio. Com efeito, essa sugere que as alterações climáticas, causadas pela poluição, teriam influência tanto em países do norte-global quanto nos do sul; tanto no continente europeu quanto no africano, americano ou asiático. O mesmo acontecia com a biodiversidade: quanto menos essa ocorresse, menos possibilidades a humanidade teria de preservar formas de vida únicas. Ou seja, tanto as ações nefastas à natureza levadas a cabo em países do norte-global, quanto aquelas que teriam lugar em países do sul-global, influenciariam não apenas o âmbito local ou regional, mas o meio ambiente global.

Aliado ao que discutimos acima, existe outro dado interessante para análise. Os conferencistas presentes no Rio defendiam que apesar de toda a humanidade ter responsabilidades sobre o meio ambiente e preservação da natureza, elas não deveriam ser as mesmas para os paises. Com isso se queria enfatizar que na degradação da natureza existiam aqueles que mais o faziam, dado o seu maior grau de poluição industrial, quanto àqueles que menos o faziam - ou, quando o fizessem, era em busca de recursos básicos para sua sobrevivência. Assim sendo, apesar de incorporarem a dimensão global dos problemas ambientais, os conferencistas dividem as responsabilidades de cada um dos agentes na sua solução.

É nesse papel diferenciado na preservação da natureza e do meio ambiente que encontramos

\footnotetext{
6 United Nations. 1992. Report of the United Nations Conference on Environment and Development: resolutions adopted by the conference. Rio de Janeiro, 3-14 Jun. Acessado em 15 jul. 2018, https://www.un.org/esa/dsd/agenda21/Agenda\%2021.pdf.
} 
uma das caracteristicas mais significativas da narrativa ambientalista global renovada no Rio. Com efeito, para os conferencistas, a solução dos problemas ambientais em regiões como a África passava necessariamente por estas se abrirem ao neoliberalismo económico, aceitando em seus territórios a presença de capital estrangeiro, sobretudo na exploração de suas commodities. ${ }^{7}$ Aos paises do norte-global cabia enviar capital econômico significativo para as regiões do sul-global, fazendo com que a sua presença comercial e empresarial significasse uma maior captação de divisas pelos estados africanos e, consequentemente, estes estariam em melhores condições de reduzir os altos índices de pobreza. Ao assim proceder, considera o documento, as populações desses países teriam o suficiente para que se pudessem alimentar, abstendo-se, dessa forma, da necessidade de agredirem a natureza em busca de seu sustento cotidiano. É nesse espírito que Jack Hollander (2003) - ao contrário da literatura acadêmica neomalthusiano, que defende que quanto mais acesso ao consumo o homem tem mais agride a natureza e o meio ambiente - enfatiza que o grande vilão da natureza em África é a pobreza. Daí que sugere que um esforço efetivo visando a preservação da natureza passava necessariamente pela sua erradicação. E tal esforço constituiria, considera o autor, obrigação moral, ética e pragmática de grupos e países ricos para com os pobres.

Defendemos, contudo, que essa colocação da nova narrativa ambientalista global é ambigua. Ao mesmo tempo que incentiva o capital internacional a explorar e expatriar os recursos naturais, como forma de deixar renda nos países pobres para que estes matem a fome; sugere que os referidos países não tomassem os seus recursos naturais, especialmente os florestais e faunísticos, como meio de sobrevivência de suas comunidades. Ou seja, enquanto os países do norte-global, de onde provinha o capital econômico internacional, deveriam intensificar a extração e exploração de recursos naturais do continente, os africanos deveriam preservar a sua fauna e flora por forma a que se garantisse a ocorrência da biodiversidade.

Essa ambiguidade é igualmente discutida por Maria Meneses (1999). Para essa autora, existe uma tensão na apropriação da natureza em África. Enquanto os agentes do norte-global, impulsionados tanto pela indústria turística quanto pela farmacêutica, tomam a natureza e a biodiversidade como fontes geradoras de divisas, desencorajam as comunidades locais africanas de desfrutarem do valor de uso da natureza a seu redor. Por forma a clarificar tal tensão, Steve Johnson (2004), toma o exemplo do projeto conservacionista Tchuma Tchatho (em Moçambique) e mostra como esse impedia que as comunidades locais tomassem a flora e fauna a seu redor como o garante de seu sustento, privilegiando a prática de safari por turistas estrangeiros.

A narrativa ambientalista global renovada no Rio, e que teve como uma de suas características dominantes a ideia de que seria possivel resolver os problemas ambientais dos países pobres por via da liberalização de suas economias e pela assistência financeira e técnica dos países do norte-global, revelou suas limitações. Elas foram reconhecidas pelos Chefes de Estado e de Governo que, vinte anos depois, em Johanesburgo, chegaram à conclusão de que o discurso ambientalista global estava sendo posto em causa pela inação de alguns países do norte-global:
A rápida integração dos mercados, a mobilida- de de capitais e o crescimento de investimentos pelo mundo abrem novos desafios e oportu- nidades para o alcance do desenvolvimento sustentável. Contudo, os benefícios e custos da globalização são desigualmente distribuidos, sendo os paises em vias de desenvolvimento os mais prejudicados. Deste modo, por forma a que possamos alcançar nossas metas de desenvolvimento, apelamos aos paises desen- volvidos que ainda não têm encetados esforços concretos para o alcance das metas oficiais de assistência ao desenvolvimento internacio- nalmente acordados, que cumpram com seu comprometimento (United Nations 2002, 3-4).8

\footnotetext{
7 United Nations. 1992. Report of the United Nations Conference on Environment and Development: resolutions adopted by the conference. Rio de Janeiro, 3-14 Jun. Acessado em 15 jul. 2018, https://www.un.org/esa/dsd/agenda21/Agenda\%2021.pdf.

8 United Nations. 2002. Report of the World Summit on Sustainable Development. Johannesburg, 26 Aug-4 Sep. Acessado em 17 jul. 2018 https://digitallibrary.un.org/record/478154\#record-files-collapse-header.
} 
Tratou-se de um reconhecimento de que a redução da pobreza e os problemas ambientais dos paises do sul-global não estavam sendo resolvidos pela globalização do neoliberalismo. Ao contrário, notam os estadistas, a pobreza tendia a persistir, o saneamento do meio continuava degradado, a deflorestação persistia, bem como as mudanças climáticas continuavam afetando países pobres e em situação de vulnerabilidade. Tentando explicar o fracasso desse comprometimento desenvolvimentista global, M. Bertrand (2004) defende que ele se devia ao fato de os países do norte-global terem passado a se preocupar mais com suas agendas nacionais, deixando as questões globais para segundo plano. Estava em causa uma disputa pelos recursos naturais de África entre os países do norte-global, o que os fazia deixar de lado os consensos anteriormente alcançados. Ao mesmo tempo, países emergentes, com destaque para a China passaram a ver no continente africano uma importante fonte de recursos naturais para suprir as necessidades de sua agenda desenvolvimentista (Giddens 2009; Vossole 2013; Dijk 2009; Brautigam 2009).

\section{África, a narrativa ambientalista global e a busca pelo desenvolvimento}

Os primeiros documentos que refletiam o posicionamento africano sobre desenvolvimento e questões ambientais na década de 1970 tinham a particularidade de indicarem a adesão do continente ao então emergente discurso ambientalista global. Nesse sentido, logo após a declaração dos consensos de Estocolmo, a Organização da Unidade Africana (OAU, na versão inglesa), reunindo vários chefes de estado e de governo do continente em Addis Abeba, divulga a Declaração Africana sobre Cooperação, Desenvolvimento e Independência Econômica. Este documento, na senda do de Estocolmo, reafirma no seu $44^{\circ}$ artigo, o comprometimento dos líderes africanos em colocarem as demandas ambientais globais em suas agendas locais de desenvolvimento, "assegurando, assim, que os países africanos fossem guiados, em todas as circunstâncias, pelos princípios adoptados pela conferência de Estocolmo sobre o meio ambiente" (African Union 1973, 1005). ${ }^{9}$

Um segundo aspecto relevante que se pode reter do documento é o fato dele apresentar uma narrativa identitária reveladora de um forte sentido de pertença ao continente, orientado por uma abordagem que pautava pela busca de um desenvolvimento endógeno. Com efeito, verifica-se a presença de uma narrativa que sugere que os países africanos deveriam ser responsáveis pelo seu próprio desenvolvimento e que, querendo estender a cooperação internacional, esta deveria ser prioritariamente a nivel continental. No que diz respeito à relação com a natureza, isto implicaria, sugere o documento, que os paises deveriam potenciar a exploração conjunta de seus recursos naturais, bem como facilitar o acesso ao mar aos países interioranos.

O norte-global aparece no documento de forma marginal. Isto é deveras significativo quando se toma em consideração a questão do meio ambiente, dado que, como demostramos mais atrás, na conferência de Estocolmo, do Rio e mesmo na de Johanesburgo, aquele bloco de paises havia confiado a si o papel de tutores ambientais do sul-global. Este não era o caso na emergente agenda desenvolvimentista africana. Embora o documento reconheça os consensos de Estocolmo, em nenhum momento nele se aventa a possibilidade de serem os países do norte-global e suas instituições a fazerem tal tutoria ambiental, nem tampouco a financiarem o desenvolvimento dos países africanos. Pelo contrário, ele é categórico ao afirmar que, para que o continente se desenvolvesse seria necessário que a elite dirigente, "com certa urgência e de forma efetiva, mobilize os recursos domésticos do continente para que estes constituam sua principal base de desenvolvimento" (African Union 1973, 1008).10

É exatamente este último ponto que nos aju-

\footnotetext{
9 African Union (AU). 1973. Declaration on African Cooperation, Development, and Economic Independence. International Legal Materials 12 ( 4): 996-1013. Acessado em 20 jul. 2018, https://doi.org/10.1017/S0020782900044077.

10 African Union (AU). 1973. Declaration on African Cooperation, Development, and Economic Independence. International Legal Materials 12 ( 4): 996-1013. Acessado em 20 jul. 2018, https://doi.org/10.1017/S0020782900044077.
} 
da a perceber o lugar que a natureza e seus recursos representavam para os líderes africanos da década de 1970. Constituíam a alavanca que impulsionaria o rápido desenvolvimento de África, o que levaria o continente a uma segunda independência, a econômica. Isso fica evidente no documento, entre outros, quando este sugere que seria importante que se fizesse: "um levantamento sistemático de todos os recursos [naturais] africanos, tendo em horizonte seu uso racional, exploração conjunta e apropriada, por forma a que se acelere o desenvolvimento do continente" (African Union 1973, 1000). ${ }^{11}$

A narrativa, segundo a qual os recursos naturais constituiriam a força motriz do rápido desenvolvimento de África vai ser renovada no final da década de 1970. Com efeito, de entre as várias diretrizes assumidas na Declaração de Monróvia, em 1979 , encontra-se uma que reforça a ideia de que os recursos naturais deveriam estar ao serviço do desenvolvimento, sugerindo que se incrementasse:

[A] cooperação no âmbito do controle de recursos naturais, exploração, extração e seu uso para o desenvolvimento da nossa economia e benefício de nossos povos, assim como a criação de instituições adequadas para se atingirem esses fins (African Union 1979, 4).12

Esse interesse em se pensar o desenvolvimento de África a partir de seus recursos naturais, como o demostraram as declarações de Addis Abeba e Monróvia, respectivamente, ganhou renovado vigor no início do novo milénio. É assim que, no ano de 2001, alguns países africanos aglomerados na União africana - nova designação da Organização da Unidade Africana - decidiram criar uma estratégia conjunta de desenvolvimento. Tratava-se da Nova Pareceria para o Desenvolvimento de África (Nepad). Na essência, ela se propunha a conceber uma po- lítica desenvolvimentista feita pelos africanos para servir aos africanos, livrando as populações da situação de pobreza que estavam sujeitos devido a extrema dependência relativamente aos credores europeus e norte-americanos. ${ }^{13}$ Nela, contudo, a preponderância da natureza e do meio ambiente para o desenvolvimento volta a estar presente. Este fato fica demostrado na forma como as elites dirigentes signatárias da NEPAD caracterizavam o continente, resumindo-o a quatro elementos constitutivos:

[Primeiro elemento] O rico complexo de depósito de mineral, petróleo e gás, a flora e a fauna natural não explorada que proporcionam uma base para a actividade mineira, agricola, turismo e o desenvolvimento industrial.

[Segundo elemento] O pulmão ecológico proporcionado pela floresta tropical húmida e a presença mínima de emissões e de efluentes nocivos ao meio ambiente num património público global que beneficia toda a humanidade.

[Terceiro elemento] Os locais paleontológicos e arqueológicos que contêm provas das origens da terra, vida e da raça humana e os habitats naturais contendo uma variada gama de flora e fauna, espécies animais únicas e os espaços abertos e inabitados que caracterizam o continente.

[Quarto elemento] A riqueza cultural da África e a sua contribuição a uma variedade de culturas da comunidade global (NEPAD 2001, 3).14

De entre os quatro elementos, como se pode constatar, apenas o último - que se refere à variedade cultural - é que não diz respeito à natureza ou ao meio ambiente. Todos os outros, como se vê, definem a África como um repositório riquíssimo de recursos naturais prontos a serem explorados.

Um aspecto crítico desta renovada narrativa desenvolvimentista africana, ao contrário das que anteriormente discutimos, é o lugar reservado aos paises do norte-global. Com efeito, ao mesmo tempo que os lideres do continente se propõe empreender uma independência econômica,

\footnotetext{
11 African Union (AU). 1973. Declaration on African Cooperation, Development, and Economic Independence. International Legal Materials 12 (4): 996-1013. Acessado em 20 jul. 2018, https://doi.org/10.1017/S0020782900044077.

12 African Union (AU). 1979. Declaration and resolutions adopted by sixteenth ordinary session of the assembly of heads of states and government. Assembly of Heads of State and Government: Sixteenth Ordinary Session. 17-20 jul. Acessado em 30 jul. 2018 , https://au.int/sites/default/files/decisions/9526-assembly_en_17_20_july_1979_assembly_heads_state_government_sixteenth_ordinary_session.pdf. 13 Nepad. 2001. A nova parceria para o desenvolvimento de África. Acessado em 19 jun. 2018, http://library.fes.de/pdf-files/bueros/ angola/hosting/nepad.pdf.

14 Nepad. 2001. A nova parceria para o desenvolvimento de África. Acessado em 19 jun. 2018, http://library.fes.de/pdf-files/bueros/ angola/hosting/nepad.pdf.
} 
pondo os africanos como agentes de seu próprio desenvolvimento, consideram que só poderão fazê-lo com o apoio daqueles que chamam de parceiros internacionais. O argumento para isso é o de que, a comunidade internacional também participou na pauperização do continente, especialmente pelo colonialismo, dai ter o dever de contribuir para o seu desenvolvimento:

A África reconhece as injustiças históricas seculares e a necessidade de as corrigir. A injunção central da nova parceria é, todavia, no sentido de esforços combinados que devem melhorar a qualidade de vida das populações africanas, 0 mais rapidamente possivel. Para isso, há responsabilidades partilhadas e beneficios mútuos para a África e os seus parceiros (Nepad 2001, 58). ${ }^{15}$

A referida responsabilidade partilhada é apresentada ao longo do documento como sendo a predisposição desses parceiros internacionais de investirem no continente, de abrirem as fronteiras de seus países para produtos africanos, assim como a prestação de monitoria e assessoria às várias iniciativas de desenvolvimento ao longo do continente. Acima de tudo, a ideia prevalecente é a de que esta iniciativa desenvolvimentista contava com o suporte financeiro e técnico dos países do norte-global.

Fica claro que a renovada agenda desenvolvimentista africana não enfatizava a ideia de que os africanos deveriam se constituir efetivamente em donos de seus destinos, incentivando, por exemplo, que paises do continente procurassem investir no mesmo espaço continental, criando um movimento de solidariedade e interdependência econômica entre os diferentes estados, como sugeria a narrativa desenvolvimentista e emancipatória da década de 1970. Longe disso, os países do norte-global aparecem na narrativa como aqueles que, pelo incremento da expansão de seu capital econômico e prestação de assessoria técnica e financeira, tomariam protagonismo no processo de desenvolvimento do continente. E, para estes, conforme vimos neste artigo, desenvolver o continente significava, também, que os africanos deveriam refrear a agressão da natureza e preservassem a biodiversidade, em troca de apoios internacionais para a eliminação da pobreza.

Nessa agenda desenvolvimentista africana, contudo, não se verifica aquilo que Leff (2006) sugeriu serem mecanismos de resistência ao capitalismo ecológico dissimulado nas políticas neoliberais e assistencialistas globais, onde as comunidades, no caso particular os estados africanos, buscariam se apropriar dos seus recursos naturais e usá-los tendo em vista sempre os interesses locais, mas que os mesmos fossem geridos de forma participativa, democrática e sustentável.

\section{Considerações finais}

A grande conclusão que pudemos chegar neste artigo é a de que a questão ambiental, longe de pacífica, encerra disputas entre países e regiões. Com efeito, a análise começa por demostrar que os paises do norte-global construiram uma narrativa global, por meio da ONU, que definia a imperiosidade da incorporação do principio da sustentabilidade ambiental nas agendas desenvolvimentistas dos países. Nessa narrativa, contudo, o continente africano era visto como incapaz de fazê-lo, por causa da pobreza aí dominante. 0 continente precisaria, indica a narrativa, do suporte e assistência dos paises do norte-global para combater a pobreza e, consequentemente, impedir que suas populações agredissem a natureza e seus ecossistemas em busca de meios de subsistência. Isto, contudo, significou um empreendimento discursivo visando legitimar a expansão do neoliberalismo e das políticas assistencialistas para o continente africano, o que punha em causa a efetivação de uma agenda desenvolvimentista autóctone e emancipatória que via na abundância de recursos naturais, o meio a partir do qual se alcançaria esse desiderato.

Essa pretensão não acontecia, também, pelo fato de os lideres africanos não terem conseguido, pelo menos no âmbito da União Africana, criar agendas alternativas de desenvolvimento que fossem capazes de contornar os mecanismos

15 Nepad. 2001. A nova parceria para o desenvolvimento de África. Acessado em 19 jun. 2018, http://library.fes.de/pdf-files/bueros/ angola/hosting/nepad.pdf. 
econômicos, técnicos e discursivos de dominação presentes nas políticas neoliberais e de assistencialismo impostas pelos países do norte-global.

\section{Referências}

Acslard, Henri. 2002. Justiça ambiental e construção social do risco. Desenvolvimento e Meio Ambiente 5: 49-60. https://doi.org/10.5380/dma.v5io.22116.

Bertrand, M. L'Onu. 2004. Paris: La Découverte.

Brautigam, Deborah. 2009. The dragon gift: the real story of China in Africa. New York: Oxford University Press.

Cabral, Amilcar. 1980. A cultura nacional. In Amilcar Cabral, organizado por Carlos Comitini, 53-93. Rio de Janeiro: Codecri.

Dijk, Meine Pieter V. 2009. The new presence of China in Africa. Amsterdan: University Press.

Dos Santos, Theotonio. 2011. Imperialismo y dependencia. Caracas: Biblioteca Ayacucho

Escobar, Arturo. 2004. Beyond the third world: imperial globality, global colonility and anti-globalisation social movements. Third World Quarterly 25 (1): 207-230. https://doi.org/10.1080/0143659042000185417.

Giddens, Anthony. 2008. Sociologia. Lisboa: Galouste Gulbenkian.

Giddens, Anthony. 2009. The politics of climate change. Cambridge: Polity Press.

Hannigan, John. 2006. Environmental sociology. 2 ed. London: Routledge. https://doi. org/10.4324/9780203001806.

Hollander, Jack. 2003. The real environmental crisis: why poverty, not affluence, is the environment's number one enemy. Berkeley: University of California Press.

Hovet Jr., Thomas. 1964. The role of Africa in the United Nations. The Annals of the American Academy of Political and Social Science 354 n. 1: 122-134. https://doi.org/10. $1177 / 000271626435400114$.

Johnson, Steve. 2004. The Tchumo Tchato project in Mozambique: community-based natural resource management in transition. In Rights, resources and rural development: community-based natural resource management in Southern Africa, editado por Christo Fabricius, Eddie Koch, Stephen Turner e Hector Magome, 210-222. London: Earthscan.

Leff, Enrique. 2006. Racionalidade ambiental: a reapropriação social da natureza. Rio de Janeiro: Civilização Brasileira.

Meneses, Maria. P. G. 1999. A natureza, a biodiversidade e o conhecimento local: qual o papel dos cientistas sociais? Estudos Moçambicanos 17: 257-276.

Mondlane, Eduardo. 1995. Lutar por Moçambique. Maputo: Centro de Estudos Africanos.
Monteiro, Armindo. 1939. Portugal in Africa. Journal of the Royal African Society 38 (151): 259-272. https://doi. org/10.1093/oxfordjournals.afraf.a101200.

Moreira, Adriano. 1961. Política de integração. Lisboa: Bertrand.

Moreira, Adriano. 1956. Política ultramarina. Lisboa: Junta de Investigação do Ultramar.

Nayyar, Deepak. 2013. A corrida pelo crescimento: paises em desenvolvimento na economia global. Rio de Janeiro: Contraponto.

Nyerere, Julius. 1968. Ujamaa: essays on socialism. Dar-Es-Salam: Oxford University Press.

Vossole, J. V. 2013. A crise de legitimidade da governança climática global: combinação de uma perspectiva marxista e polanyiana. Revista Critica de Ciências Sociais 100: 153-176. https://doi.org/10.4000/rccs.5275.

\section{André Victorino Mindoso}

Doutor em Sociologia pela Universidade Federal do Paraná (UFPR), Curitiba, PR, Brasil. Docente de Sociologia na Faculdade de Letras e Ciências Sociais da Universidade Rovuma (UniRovuma), Nampula, Moçambique. 